\title{
The Role of Serious Games, Gamification and Industry 4.0 Tools in the Education 4.0 Paradigm
}

\author{
Fernando Almeida \\ University of Porto, Portugal \\ ORCID: 0000-0002-6758-4843 \\ Jorge Simoes \\ Higher Polytechnic Institute of Gaya, Portugal \\ ORCID: 0000-0002-7822-0068
}

\begin{abstract}
Education 4.0 is a new educational paradigm that intends to address the needs and potentialities of the fourth industrial revolution. Education 4.0 builds on the concept of learning by doing, in which students are encouraged to learn and discover different things in singular ways based on experimentation. This study intends to analyze the role of emerging technologies like serious games and industry 4.0 in the transformation of education 4.0 in higher education. A qualitative methodology was employed based on 25 case studies of innovative projects in Portuguese higher education institutions. The results indicate a residual adoption of serious games and gamification approaches only appear in less than $20 \%$ of the projects. It was also possible to identify that most projects involve several stakeholders such as teachers, students and university managers, and typically involve multidisciplinary competencies fields. The main benefits brought to the education context include greater involvement of students in projects, development of their skills and its application in a real context. On the other hand, the main challenges are the simplification of the real world made by these applications, the difficulties inherent to their inclusion in the didactical system and the limited capacities to offer greater interactivity without predefined external stimuli.
\end{abstract}

Keywords: Education 4.0; Industry 4.0; Serious games; Gamification; Educational paradigm

\section{Introduction}

There is currently an increasing recognition of the strategic importance of higher education for economic and social development. Higher education has been giving ample demonstrations of its importance to promote transformations in society, so it has become part of the list of topics considered as priorities and strategic for the future of the nations. There is a growing conviction that economic and social development requires more and more the education levels of the population. In addition, it is established that the current labor market increasingly demands skilled, agile and flexible professionals (Martinaitis, 2014). Soft skills like teamwork, communication and resilience have progressively gained greater importance in the context of the expected qualifications of a recent graduate. 
These new expectations of formation assume rupture with rigid and, in many cases, undifferentiated patterns of higher education. It also implies changes in the training profile, qualifying students in the field of knowledge, in the ability to apply knowledge creatively in the solution of concrete problems, in the development of a spirit of leadership and functional polyvalence, as well as in the greater adaptability to technological change (Burner, 2018). In fact, the current information and communication technologies have originated changes and transformations in different segments, and the education field is not an exception.

In the field of education, technological advances have allowed the emergence of distance learning and fostered greater innovation in teaching methods inside and outside the classroom. The inclusion of games in educational contexts, known as serious games, still generates a lot of controversy between teachers and society. Still seen by many people as a playful activity, serious games in an educational context promote the development of skills and abilities through immersive experiences. On the other hand, the emergence of new technologies has fostered the appearance of new businesses and social interaction models (Ibarra et al., 2018; Liao et al., 2017; Schönsleben et al., 2017). The concept of industry 4.0 is progressively used in research, academic and industry communications, which is defined by Rojko (2017) as the integration of emergent technical and business processes in companies supported in the technologies of Internet of Things (IoT), virtualization and smart factory.

In fact, the technologies such as smart sensors, big data and 3D printing have been used successfully in the business sector and have contributed to economic and social development. However, its adoption in the education system is still an unexplored issue. In this sense, the objective of this study is to analyze the current state of incorporation of serious games and industry 4.0 tools in the classroom and to understand how these two paradigms can be used together to foster a more innovative learning. Additionally, this study also intends analyzing the advantages and challenges of incorporating these technologies in the classroom. Therefore, the following research questions were established:

- RQ1 - Do the projects uniformly address the topics of serious games, gamification and Industry 4.0 ?

- RQ2 - Which scientific areas are included in the projects?

- RQ3 - What are the main benefits brought to the educational context?

- RQ4 - What are the main challenges and difficulties of their inclusion in the educational context?

RQ1 intends to analyze how the concept of serious games, gamification and Industry 4.0 tools is used in higher education institutions and it is intended to understand how these concepts are used together. RQ2 intends to organize the projects by scientific areas to realize which scientific areas have attracted a greater interest from the academic community. Finally, RQ3 looks at the key benefits brought by the adoption of those practices in the educational context and, on the other side, RQ4 looks at the main challenges and difficulties.

The study is organized as follows: initially a literature review on education 4.0 concept and gamification techniques in higher education is performed. Then, the methodology and considered cases studies are presented and, subsequently, the results are presented and 
discussed according to research questions. Finally, the conclusions and limitations of this study are summarized.

\section{Literature Review}

\section{The Concept of Industry 4.0 and Education 4.0}

It becomes possible to identify four paradigms of educational evolution, with the emergence and advancement of new technologies as the main catalyst for the appearance of new educational paradigms. According to Demartini and Benussi (2017), the four paradigms of education can be found during the last twenty years. The education 1.0 paradigm offers a traditionally expository model in which the evaluation is mainly based on written and oral assessments; in the education 2.0 paradigm emerges the importance of the projects developed in a group using open technologies (like Arduino) in the context of the institution and classroom; in the education 3.0 social networks play a key role in creating a more open environment in which pupils' creativity and participation are encouraged outside the boundaries of the course and institution; finally, education 4.0 is presented as an emerging paradigm, but in which learning models are adapted and customized according to real-time learner profiles. Artificial Intelligence (Al) emerges as the main technology's enabler of the education 4.0 (Popenici \& Kerr, 2017). Three technologies were added by Shahroom and Hussin (2018) that include also the loT, Virtual Reality (VR) and Augmented Reality (AR).

The role of teachers and students during the evolution of educational paradigms has also changed. The teacher's knowledge became broader, not restricted exclusively to the domain of programmatic content, but teachers also have information about how these contents are assimilated by the students supported by an Al-based learning portal. On the other hand, the student's role has also undergone significant changes, from mainly passive in education 1.0 to more autonomy in education 4.0 (Demartini \& Benussi, 2017). Puncreobutr (2016) argues that the evolution of economic paradigms has also led to the emergence of new educational paradigms. Launkaew (2016) considers that the current economic model of 4.0 supported by the hyper-connectivity of devices and the diffusion of innovation fostered the emergence of Social \& Virtual Learning Environments. In the same direction, Xing and Marwala (2017) state that the appearance of industry 4.0 will lead to a greater interdisciplinary of teaching, research, and knowledge.

The industry 4.0 revolution will necessarily have an impact on the education system with the emergence of education 4.0 paradigm. Bughin et al. (2018) advocate that it is important to ensure that future workers will be highly trained in emerging technologies, but also to develop interdisciplinary skills that will enable them to develop reflective thinking. In the future, the greatest challenge for citizens will be to use such diverse panoply of knowledge and skills in the search for innovative solutions leveraged by emerging technologies (Islam, 2018).

The education 4.0 paradigm empowers students to define their own model and pace of learning. According to Bartolomé et al. (2018), two fundamental characteristics of education 4.0 is the personalization and flexibility. In this sense, adaptive learning systems play a fundamental role in the education 4.0 paradigm (Kara \& Sevim, 2013). In the adaptive learning model, technology is used to propel learning according to the specific needs of each student. The students' profile and their learning needs are known through the use of advanced 
programming logic, in which artificial intelligence, big data, and cloud computing play a fundamental role (Kinshuk, 2016). Additionally, Murray and Pérez (2015) consider that adaptive systems positively impact other aspects of the educational process, such as student persistence and engagement.

Education 4.0 occurs in complex virtual learning environments (VLEs), where there is a greater need to have interactive and collaborative educational components (Richert et al., 2015). VLEs allow student learning to be more free, exploratory, immersive and adaptive (Barker \& Gossman, 2013; Demian \& Morrice, 2012; Richert et al., 2015). A key point in the adoption of VLEs is the technological dimension. In this sense, the use of emerging technologies such as robotics and virtual reality emerge as educational practices in pioneering projects (Hayati \& Hashemy, 2013; Martín-Gutiérrez et al., 2017; Sung et al., 2013).

The importance of integrating smart learning environments into the learning ecosystem and educational contexts is also referred in literature. Gros (2016) advocates the adoption of innovative uses and new pedagogical approaches in both formal and informal learning processes. Zhu et al. (2016) complements this study by defining ten features that a smart learning environment should have: (i) location-aware; (ii) context-aware; (iii) socially-aware; (iv) interoperable; (v) seamless connection; (vi) adaptable; (vii) ubiquitous; (viii) whole record; (ix) natural interaction; and ( $x$ ) high engagement. Additionally, smart learning environments supported by the use of technology are more student-centered and less time consuming (Hariharasudan \& Kot, 2018).

\section{Gamification and Adoption of Serious Games in Higher Education}

Gamification is an emerging phenomenon, which stems directly from the popularization and popularity of games, and its intrinsic capabilities to motivate action, solve problems and enhance learning in the most diverse fields of knowledge and life of individuals. According to Alsawaier (2018) gamification includes the adoption of game mechanics and dynamics to engage people, solve problems and improve the learning process. Initially, gamification techniques were applied in marketing programs and Web applications, in order to motivate, engage and retain customers and users (Zichermann \& Cunningham, 2012). Gamification presupposes the use of elements traditionally found in games, such as narrative, feedback, rewards system, conflict, cooperation, competition, clear objectives and rules, levels, trial and error, fun, interaction, interactivity, among others, in other activities that are not directly associated with games (Khaleel et al., 2016; Sailer et al., 2017).

Some broad lines must be adopted for the application of gamification as a method of transforming teaching and learning processes through the use of strategies and thoughts on the game. Simões et al. (2013) propose a virtual online learning environment, in which the following guidelines should be adopted:

- Provide multiple paths to arrive at a solution of the problem, so that the educative experience of each player if differentiated;

- Give quick feedback to the player about their actions and decisions throughout the game;

- Provide different levels of difficulty for the proposed challenges, in order to allow that each player have their own learning pace;

- Divide complex tasks into smaller ones, so that knowledge is acquired gradually; 
- Include the error as part of the learning processes and promotes that the player reflect on the reasons for their mistakes;

- Build a narrative context for the game, so that the actions of the characters make sense;

- Promote competition and collaboration throughout the various stages of the game;

- Ensure that the game is fun for the player to guarantee that they feel an immersive experience.

Dicheva et al. (2015) provide an overview of published studies on gamification principles until 2015. The top three most adopted design principles are: (i) visible status; (ii) social engagement; and (iii) freedom of choice. On the other side, personalization and time restrictions are considered two of the less relevant features in published studies on gamification. The Gamification concept is often confused with serious games. In fact, both terms share many common elements, but it is necessary to differentiate them. Gamification uses gaming codes and other elements commonly found in games to make an existing training more attractive and fun. Elements such as rewards, recognition and competition among peers are added to an existing training. On the other hand, a serious game is a training offered on the form of a game or simulation, which was built to meet the specific needs of a group (Laamarti et al., 2014).

Serious games can be seen as games that involve goal-oriented tasks that target both realworld and non-real-world scenarios, which aim to improve the player's performance and cognitive abilities (Shi \& Shih, 2015). They are being used in corporate training, education, problem solving, military training, healthcare, public management etc. Serious games offer a significant number of benefits, such as making players feel responsible for success according to their actions, combining high-quality content, showing great involvements, and turning errors into learning elements (Papanastasiou et al., 2017; Tsekleves et al., 2016). These games provide feedback in various formats, such as: tables, graphs, texts, multimedia, peer feedback synchronously and asynchronously, and assessments that can be leveraged to support learning across multiple scenarios (Bellotti et al., 2013).

The process of designing a serious game is necessarily complex and involves multidisciplinary skills Bellotti et al. (2010) state that there isn't an unequivocal answer to the challenges of confronting the creative experience when designing a serious game. In fact, everything must be carefully designed and developed according to the specific use that will be made of the serious game, target group, skills, preferences, and experience with these tools. The central role of the teacher is to determine if a good balance between fun and learning can be achieved (Slimani et al., 2016).

Serious games have been successfully used in many contexts. Cheng et al. (2015) discuss the use of serious games in science education, revealing that most games are adventure or roleplaying. Sera and Wheeler (2017) propose the use of serious games in health professional education, namely by its integration in the pharmacy curricula. Finally, it is also worth mentioning the project developed by Bahadoorsingh et al. (2016), in which serious games are used in the training of engineers, particularly in the design and analysis of power distribution networks. 


\section{Methodology}

\section{Research Design}

A qualitative methodology was adopted in the development of this study because the role of serious games in education 4.0 is still an emergent topic. In this sense, this approach allows us to explore multiple perspectives on the topic (Queirós et al., 2017). It has also been applied the field research method, which allows us to have a deep perception how teachers are employing serious games, gamification techniques and Industry 4.0 tools to engage students in the classroom and provide them with more immersive experience. Additionally, Blackstone (2012) states that field research methods allow us to explore social facts and contextual information that may not appear initially relevant. This situation is fundamental for our study since it allows us to explore and analyze the difficulties and good practices that may be applied to the inclusion of serious games in education 4.0.

\section{The Sample}

This study uses as primary information source the essay of the Foundation for Science and Technology (FCT) in collaboration with the Directorate General for Higher Education (DGES) in Portugal that in 2015 presented the results of innovative projects in didactic innovation in Portuguese higher education. This is the most recent study in Portugal on the adoption of innovative educational practices in higher education that simultaneously include the use of serious games and emerging practices in the field of internet of things, augmented reality, big data, cloud computing, among others. In the context of this competition, 181 applications were submitted, with 35 projects being proposed for funding and 33 being completed. Of these 33 completed projects, 25 of them were considered successful cases by supporting agencies (DGES and FCT). Consequently, this study includes a sample of 25 education 4.0 case studies. There are no data available on the 8 failure causes that could help us to identify their causes and propose mitigation actions.

\section{Data Collection Tools}

The data collection process focused on the 25 cases of innovative practices in Portuguese higher education. For this purpose, the assessment and evaluation report of these projects was accessed. This approach was very useful to understand the advantages offered by each project and the adopted technologies and industry 4.0 tools. Furthermore, the promoters of each project reflect in this report the difficulties experienced in each phase of the project. These elements proved to be equally important for the discussion of the results.

The authors recorded each project with a unique identifier. For each of them, information was collected on their title, scientific area, the indication of the use of serious games or gamification practices and a list with the adopted industry 4.0 tools. In order to increase the reliability of this process, each of the authors individually recorded this information and these elements were subsequently discussed to identify potential divergent assessments. 


\section{Research Process}

The various phases of the adopted methodology are depicted in Figure 1. In the first phase (preliminary stage) a literature review on the conceptualization of education 4.0 concept and the exploration of gamification and serious games in higher education is performed. Subsequently, in the fieldwork stage, the research questions are defined and the data of the essay provided by FCT and DGES is analyzed. Finally, in the interpretation stage, a cross-case analysis is performed to understand the similarities and differences between the 25 successful projects. Also, in this phase, a comparative analysis of the results obtained is compared against the findings addressed in the literature and the main conclusions of this study are enunciated.

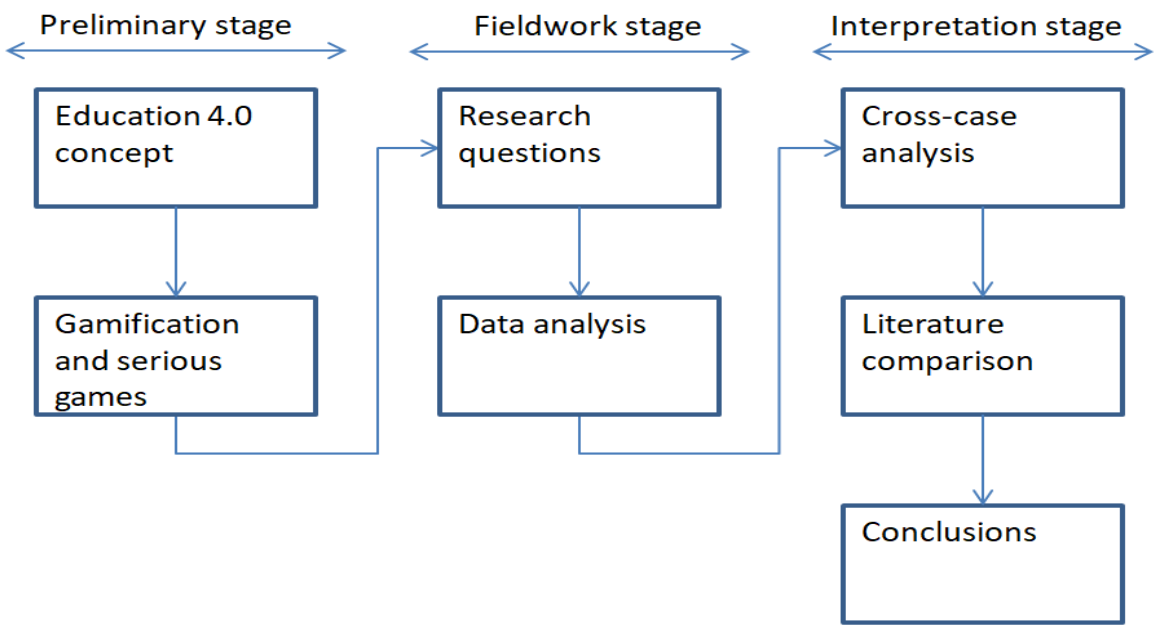

Figure 1. Phases of the adopted methodology

\section{Findings}

Table 1 presents for each study its scientific area, adopted industry 4.0 tools and indicates if serious games were used within the scope of the project. The considered scientific areas follows the FCT reference ${ }^{1}$ that presents a total of four scientific domains: (i) life and health sciences; (ii) exact sciences and engineering; (iii) natural and environmental sciences; and (iv) social sciences and the humanities. Each scientific domain is sub-divided into scientific areas. A total of 25 scientific areas are proposed by FCT.

Table 1. Analysis of the Projects According to Multiple Dimensions

\begin{tabular}{|c|c|c|c|c|}
\hline Id & Title & Scientific area & $\begin{array}{l}\text { Adoption of } \\
\text { serious } \\
\text { games and } \\
\text { gamification? }\end{array}$ & $\begin{array}{c}\text { Adopted } \\
\text { Industry } 4.0 \\
\text { tools }\end{array}$ \\
\hline CS1 & Chemistry: an experimental science & $\begin{array}{l}\text { Chemistry and } \\
\text { Chemical } \\
\text { Engineering } \\
\text { (CCE) }\end{array}$ & No & $\mathrm{n} / \mathrm{a}$ \\
\hline
\end{tabular}

${ }^{1}$ https://www.fct.pt 
CS2 Reception in Portuguese Higher Education Institutions: diagnose, share skills and values in 1st cycle students

CS3 Toolbox Construction and Validation for Curriculum Development in Higher Education

All scientific No $\mathrm{n} / \mathrm{a}$ areas of Exact Sciences and Engineering domain

CS4 Contribution to the external validation of All the multidisciplinary peer observation model

CS5 CLIL in Portuguese Higher Education building a practice and learning community

The Human No $\mathrm{n} / \mathrm{a}$ Mind and its Complexity

CS6 Modeling in the Geology class of Higher Geosciences Education: Research and Teaching

CS7 Thinking and Sharing Quality Practices in Higher Education

CS8 Transversal Skills for Science and Technology

CS9 Integrated formal and non-formal science education in the initial teacher training

Institutions, Values, Beliefs and Behavior

All

Videoconference

Reflections on a Sharing and Dissemination of Experiences in Didactic Innovation of UTAD

CS11 INITIATE - Initiation to the scientific investigation applied to the arts, archeology and architecture

CS12 Didactic Innovation in Higher Education through the ROBOT @ ESCOLA Project Robotics in School

Cultures and No $\mathrm{n} / \mathrm{a}$

Cultural

Production

Mechanical

Engineering and

Engineering Systems

Electrical

Engineering and Computer

Engineering (EECE)

Individuals, Conference

$\mathrm{n} / \mathrm{a}$ $\mathrm{n} / \mathrm{a}$

No

Institutions and Markets

All

No

n/a

a

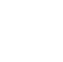




\begin{tabular}{|c|c|c|c|}
\hline $\begin{array}{l}\text { Sharing and dissemination of online } \\
\text { experimentation in engineering courses, } \\
\text { supported by wireless sensor and actuator } \\
\text { networks and multimedia content }\end{array}$ & EECE and CCE & No & $\begin{array}{l}\text { Simulation, } \\
\text { Cloud } \\
\text { computing and } \\
\text { Internet of } \\
\text { Things }\end{array}$ \\
\hline $\begin{array}{l}\text { Evaluation of the Satisfaction of } \\
\text { Pedagogical Practices in the scope of the } \\
\text { Teaching Distance from the University of } \\
\text { Coimbra }\end{array}$ & All & No & $\mathrm{n} / \mathrm{a}$ \\
\hline $\begin{array}{l}\text { Pedagogical Innovation in e-Learning: } \\
\text { Proposal of a Framework for (Self) } \\
\text { Assessment of Practices in Higher } \\
\text { Education }\end{array}$ & All & No & $\mathrm{n} / \mathrm{a}$ \\
\hline $\begin{array}{l}\text { Pedagogical and Institutional Promotion of } \\
\text { the Platform M@t-educar successfully }\end{array}$ & All & Partly & $\mathrm{n} / \mathrm{a}$ \\
\hline $\begin{array}{l}\text { MatActiva - Dissemination of Experiences } \\
\text { of Didactic Innovation in Mathematics with } \\
\text { Appeal to Technologies }\end{array}$ & All & Yes & $\mathrm{n} / \mathrm{a}$ \\
\hline $\begin{array}{l}\text { TecGEO: Design and implementation of the } \\
\text { first Massive Open Online Course (MOOC) } \\
\text { in Portuguese in the field of Science and } \\
\text { Geographical Information Systems }\end{array}$ & Geosciences & No & $\mathrm{n} / \mathrm{a}$ \\
\hline $\begin{array}{l}\text { Production of an online technical- } \\
\text { pedagogical device contributes to the } \\
\text { enrichment of learning modes }\end{array}$ & Geosciences & No & $\mathrm{n} / \mathrm{a}$ \\
\hline Guides for designing MOOC courses & All & No & $\mathrm{n} / \mathrm{a}$ \\
\hline $\begin{array}{l}\text { Materiality and Practices of Consumption } \\
\text { of Network Media }\end{array}$ & All & No & $\mathrm{n} / \mathrm{a}$ \\
\hline $\begin{array}{l}\text { Respiratory Sound Assessment Toolkit } \\
\text { (RSAT) - The auscultation of the future }\end{array}$ & $\begin{array}{l}\text { Diagnostic, } \\
\text { Therapies and } \\
\text { Public Health }\end{array}$ & No & $\begin{array}{l}\text { System } \\
\text { Integration }\end{array}$ \\
\hline
\end{tabular}

\section{Discussion of Results}

RQ1 - Do the projects uniformly address the topics of serious games, gamification and Industry 4.0?

Of the 25 studies considered only three of them (approximately 12\%) adopt serious games in the learning process. There are still two studies that adopt gamification practices through the use of leader board points and badges that seek to encourage and recognize participation. Together these two groups of studies involving serious games and gamification represent less than $20 \%$ of all studies. Video conferencing and simulation emerge as the two most commonly adopted practices in Education 4.0. The involvement of students from different faculties and courses, and the existence of projects that aim to capture students from higher school levels to university education are positive. It is also worth to mention the existence of initiatives that intend to increase student motivation for scientific areas that offer the highest employability 
rate. Similarly, it is worth emphasizing some projects that help other teachers to digitalize their classes, namely through the construction of Massive Open Online Courses (MOOC).

Studies report that videoconferencing is a useful tool in promoting a convivial classroom atmosphere because it enables two-way conversation. In this way, the learning process occurs in real time and interactively, in which the involved actors can see and listen simultaneously. Furthermore, due to the teaching tools available at universities, the teacher can add other pedagogical resources (e.g., graphics, videos, diagrams) while explaining a concept. However, it is emphasized as the main challenge the need of a personalized physical environment that guarantees a good quality of video and audio capture.

Simulation is another learning technique reported in two studies. This method allows the training of real-world activities and processes in a safe environment. In the two mentioned studies, we have the adoption of this technique in the engineering and management fields. In spite of this, the impact of the adoption of simulation techniques is not restricted to these two knowledge areas, and several authors report the use of the simulation technique in areas in which students are expected to develop skills, but in which safety and costs issues do not allow the employ of real-world experiences (Vlachopoulos \& Makri, 2017).

Other emerging technologies in the context of Industry 4.0 philosophy such as robotics, augmented reality and internet of things appear to have enormous potential in the area of education. Chong et al. (2018) emphasize the relevance of 3D printing in the classroom to help students in visualize and understand fundamental theories and concepts in the engineering field. Hussin (2018) mentions the potential of virtual and augmented reality to change the educational landscape. However, their adoption in Portuguese higher education classrooms is still residual. Some reasons for this situation are the lack of maturity of these technologies, the high technological complexity, the need for specialized knowledge and the need to draw up a teaching plan that promotes the adoption of new technologies and the involvement of teachers with multidisciplinary competencies.

\section{RQ2 - Which scientific areas are included in the projects?}

More than half of the considered studies address more than one scientific area, and there are several studies that simultaneously include all four scientific domains of the FCT framework. Within these studies, we emphasize the proposal of new pedagogical practices supported in the use of e-learning and b-learning platforms. It is also worth highlighting the creation of multidisciplinary projects between several universities and faculties, in which the contribution of each promoter can be maximized through groups dynamics and brainstorming techniques.

There are also projects in more specific and delimited scientific areas with predominance for educational projects in Chemistry and Chemical Engineering (CCE) and Electrical Engineering and Computer Engineering (EECE). It is recognized that the EECE field is the one that presents the best conditions for the adoption of Industry 4.0 tools, due to the proximity of the field to the teacher's formation background. Case study 13 (CS13) also emphasizes that maturity of students and the existence of greater technological skills is a facilitator in the adoption and inclusion of simulation models and augmented reality, having the project been implemented in a master's degree. In this sense, it was possible to use open source libraries such as VTK, OpenCV and ARToolKit which have poor support documentation particularly for newer 
devices. In this sense, the work of the students also involved an exploration component and included the development of prototypes for different purposes, such as robotic football in 3D environment, environment for musical creation, and rapid modeling from architectural plans.

The obtained findings allow us to conclude that although CCE and EECE are the two areas where the uses of industry 4.0 tools stand out, all scientific areas offer conditions for the inclusion of innovative practices in higher education. In particular, emerge multidisciplinary projects that fall within multiple scientific areas, which present innovative practices in the context of education 4.0 and involve students from various faculties and universities.

\section{RQ3 - What are the main benefits brought to the educational context?}

Table 2 summarizes the benefits brought by the adoption of serious games and industry 4.0 tools for the learning process in higher education considering each case study. The following acronyms are used: "-" means that this criterion is not found in a given study; " $Y$ " the criterion is explicitly mentioned in a given study; " $\mathrm{P}$ " means that the criterion is implicitly considered.

The development of transversal competencies is referred on three case studies (CS7, CS12 and CS13) as being a fundamental benefit to the use of these technologies by several universities and courses. Despite this, it is recognized the difficulty of the existence of measurable indicators that allow to gauge its adoption in the classroom. Equally important, highlighted on CS10, CS13 and CS16, is the promotion of critical thinking skills that are crucial to academic success, with a lifelong learning perspective and transition to the job market. On the other hand, CS12 states that the use of an IDE programming environment (i.e., Arduino) allowed the testing of algorithms developed by students on a robotic platform. This methodology brought advantages to students, since it has been a stimulating factor in facilitating the understanding of the contents through the direct analysis of the actions of the robot. One important benefit brought by the adoption of simulation practices is the intense interactivity as mentioned in CS14, in which students use a business simulation software to create companies and compete in a virtual marketplace. Finally, CS16 emphasizes the role of cloud computing in remote laboratory creation, which allowed the exploration of this solution by students with distinct skills (i.e., from computer science, chemistry and biomedical engineering).

Table 2. Classification and Comparative Analysis of Benefits

\begin{tabular}{|c|c|c|c|c|c|c|c|c|c|}
\hline Benefit & CS7 & CS10 & CS12 & CS13 & CS14 & CS16 & CS19 & CS20 & CS25 \\
\hline Skills training & - & - & $\mathrm{Y}$ & $Y$ & $Y$ & $Y$ & $Y$ & $Y$ & $\mathrm{Y}$ \\
\hline Applicable to the real world & - & - & Y & $Y$ & $\mathrm{Y}$ & Y & - & - & Y \\
\hline Immediate feedback & $P$ & $P$ & $Y$ & - & $P$ & $P$ & - & - & - \\
\hline Interactive nature & Y & $\mathrm{P}$ & Y & $Y$ & $Y$ & $P$ & - & - & - \\
\hline Collaborative learning & - & - & - & $P$ & Y & - & - & - & - \\
\hline Students engagement & - & - & $Y$ & $Y$ & - & Y & $P$ & $P$ & $P$ \\
\hline Complex problem-solving & - & - & $P$ & $P$ & - & Y & $P$ & $P$ & - \\
\hline Critical thinking & - & $Y$ & - & Y & - & Y & - & - & - \\
\hline Creativity & - & - & $P$ & $Y$ & - & - & - & - & - \\
\hline Emotional intelligence & - & - & - & $P$ & - & $P$ & - & - & - \\
\hline $\begin{array}{l}\text { Development of transversal } \\
\text { competencies }\end{array}$ & $\mathrm{Y}$ & - & $P$ & Y & - & - & - & - & - \\
\hline Personalized learning pace & - & - & - & - & - & - & $\mathrm{P}$ & $\mathrm{P}$ & - \\
\hline
\end{tabular}




\section{RQ4 - What are the main challenges and difficulties of their inclusion in the educational context?}

Table 3 looks to the main challenges and difficulties of adopting serious games and industry 4.0 tools in the educational context. The same acronyms with the same meanings are used as in the previous situation.

CS7 and CS10 use a videoconference system to allow the participation of geographically distributed audiences. In CS7 we have the use of videoconference between several universities, while in CS10 we have the construction of thematic webinars about critical thinking. Webinars are pointed out in CS10 as a dynamic and convenient way to disseminate content, being enough to have a computer or smartphone with webcam, microphone and Internet access. However, its use limits the interactivity among the participants, since the communication is carried out just on one way. Participants can only interact with each other and ask questions to the speaker via chat.

The adoption of virtual reality techniques also faces some challenges. CS13 reports difficulties in designing more complex scenarios. The use of VTK as the main graphic library simplifies the work of students in the classroom and offers a high flexibility and wide spectrum of applications in visualization, but causes some problems in the use of multiple textures, which generates some difficulty in creating more complex 3D virtual worlds. Also in this case study is mentioned difficulties in accompanying the technological evolution, since new equipment and tools appear each academic year.

It is also reported in CS16 the existence of difficulties in the use of virtual laboratories by both teachers and students. In this sense, technical support should be provided, either on the form of tutorials and/or chat, on the use and remote interaction with the equipment and software. On the other hand, it is not always easy to develop a technological application that approaches all the academic content addressed in the classroom. CS19 states that it was not possible to use the mathematical simulation platform all the semester, because it does not incorporate all contents that are part of the syllabus of the course in which it was implemented. Finally, in CS25 it is reported scalability issues, since it was not possible to offer a complete database of pulmonary auscultation sounds and to overcome some technical problems in its construction, like the simultaneous graphic visualization of breathable sounds.

Table 3. Classification and Comparative Analysis of Challenges and Difficulties

\begin{tabular}{|c|c|c|c|c|c|c|c|c|c|}
\hline Challenges and difficulties & CS7 & CS10 & CS12 & CS13 & CS14 & CS16 & CS19 & CS20 & CS25 \\
\hline $\begin{array}{l}\text { Little involvement of } \\
\text { participants }\end{array}$ & $Y$ & - & - & - & - & - & - & - & - \\
\hline Low interactivity & $\mathrm{P}$ & $Y$ & - & - & - & - & $P$ & $P$ & - \\
\hline $\begin{array}{l}\text { Effectiveness of learning } \\
\text { goals }\end{array}$ & - & - & $P$ & - & - & - & - & - & - \\
\hline $\begin{array}{l}\text { Embedment in a didactical } \\
\text { system }\end{array}$ & - & - & - & - & $\mathrm{P}$ & - & Y & - & $\mathrm{P}$ \\
\hline Technical issues & - & - & - & - & - & $P$ & - & - & $P$ \\
\hline Simplification of real world & - & - & - & $Y$ & $Y$ & - & $Y$ & $Y$ & $Y$ \\
\hline Lack of documentation & - & - & - & $P$ & - & - & - & - & - \\
\hline $\begin{array}{l}\text { Need for multidisciplinary } \\
\text { skills }\end{array}$ & - & - & $P$ & - & - & $Y$ & - & - & - \\
\hline
\end{tabular}


Rapid technological

evolution

Teacher training

Use of physical equipment

Available time

\begin{tabular}{ccccccccc}
- & - & - & $Y$ & - & - & - & - & - \\
- & - & - & $P$ & - & $Y$ & - & - & - \\
- & - & - & $Y$ & - & - & - & - & - \\
- & - & - & $Y$ & - & - & - & - & - \\
\hline
\end{tabular}

\section{Conclusions}

Serious games and industry 4.0 tools are residually adopted in higher education. Less than $20 \%$ of the case studies analyzed in the current study refer to the adoption of gamification, simulation platform, videoconferencing, internet of things and virtual reality technologies. The majority of the case studies focus mainly on the development of multidisciplinary projects involving several courses, colleges and universities under e-learning platforms. It is also verified that case studies cover typically multiple scientific areas, although there is a greater predominance of projects in the CCE and EECE fields. Despite this low penetration rate, the potential of using serious games and industry 4.0 tools is recognized as a practice to broaden, transform and innovate the curriculum, teaching practices and learning. However, it is also recognized that the use of these tools requires a change of roles, attitudes and beliefs about the learning of both students and teachers.

Main benefits brought to the education context include skills training, the greater involvement of students in class activities and their application to the real world. Therefore, the potential of these tools is proven in offering a more innovative and immersive training. However, some challenges and difficulties in its adoption are also presented, namely the simplification that most of these tools make of the real world, the difficulties of its integration in the didactical system and the limitations of the system in responding to non-predefined stimuli from the external environment.

The results of this study help us to outline some recommendations for faster and seamless integration of industry 4.0 tools into education 4.0 environments. First of all, it is important to look at the distinct profile of the students of this new generation that prefer more hands-on approaches. In this sense, industry 4.0 technologies should be progressively integrated into the demonstration of theoretical concepts, so that they can be empirically proven and tested by students. In addition, this approach will allow students to build technology-based skills and offer a more efficient and diverse model of lessons, both in the classroom and at home. Likewise, it is important that new technologies include synchronous and asynchronous communication mechanisms inside and outside the classroom. In this sense, MOOCs emerge as a fundamental element in the context of education 4.0.

It is relevant to recognize as the main limitation of this study its emphasis in Portugal, since only case studies of the application of serious games and industry 4.0 tools in Portuguese universities are considered. Hence, the results obtained must be proven and validated considering other educational contexts. Another relevant limitation of this study is the exclusive analysis of success cases of didactic innovation practices in higher education. As mentioned in this study the data analysis did not include eight failure experiences due to the inexistence of public data on these case studies. Through these experiences it could be possible to identify their causes and present mitigation actions that may constitute important lessons for future projects. Finally, the date in which those case studies were reported can also 
be considered another limitation. From 2015 until nowadays there has been a significant evolution of 4.0 technologies, hence it is likely that these technologies may also have gained greater importance in higher education institutions.

\section{References}

Alsawaier, R. (2018). The effect of gamification on motivation and engagement. International Journal of Information and Learning Technology, 35(1), 56-79.

Bahadoorsingh, S., Dyer, R., \& Sharama, C. (2016). Integrating serious games into the engineering curriculum - a game-based learning approach to power systems analysis. International Journal of Computational Vision and Robotics, 6(3), 276-289.

Barker, J. \& Gossman, P. (2013). The learning impact of a virtual learning environment: students' views. Teacher Education Advancement, 5(2), 19-38.

Bartolomé, A., Castañeda, L., \& Adell, J. (2018). Personalisation in educational technology: The absence of underlying pedagogies. International Journal of Educational Technology in Higher Education, 15(14), 1-17.

Bellotti, F., Berta, R., \& De Gloria, A. (2010). Design effective serious games: Opportunities and challenges for research. International Journal of Emerging Technologies in Learning, 5, 22-35.

Bellotti, F., Kapralos, B., Lee, K., Moreno-Ger, P., \& Berta, R. (2013). Assessment in and of serious games: An overview. Advances in Human-Computer Interaction, Article ID 136864, 1-11.

Blackstone, A. (2012). Principles of sociological inquiry: qualitative and quantitative methods. Retrieved on 10 December 2018 from https://2012books.lardbucket.org/books/ sociologicalinquiry-principles-qualitative-and-quantitative-methods/index.html

Bughin, J., Hazan, E., Lund, S., Dahlström, P., Wiesinger, A., \& Subramaniam, A. (2018). Skill Shift: Automation and the Future of the Workforce. McKinsey Global Institute. Retrieved on 10 December 2018 from https://www.mckinsey.com/ /media/McKinsey/Featured\% 20Insights/Future\%20of\%20Organizations/Skill\%20shift\%20Automation\%20and\%20the \%20future\%20of\%20the\%20workforce/MGI-Skill-Shift-Automation-and-future-of-theworkforce-May-2018.ashx

Burner, T. (2018). Why is educational change so difficult and how can we make it more effective? Forskning og forandring, 1(1), 122-134.

Cheng, M., Chen, J., Chu, S., \& Chen, S. (2015). The use of serious games in science education: A review of selected empirical research from 2002 to 2013. Journal of Computers in Education, 2(3), 353-375.

Chong, S., Pan, G., Chin, J., Show, P., Yang, T., \& Huang, C. (2018). Integration of 3D printing and Industry 4.0 into engineering teaching. Sustainability, 10, 1-13.

Demartini, C. \& Benussi, L. (2017). Do Web 4.0 and Industry 4.0 imply Education X.0? IT Pro, May/June, 4-7.

Demian, P. \& Morrice, J. (2012). The use of virtual learning environments and their impact on academic performance. Engineering Education, 7(1), 11-19. 
Dicheva, D., Dichev C., Agre G., \& Angelova G. (2015). Gamification in education: A systematic mapping study. Educational Technology \& Society, 18(3), 75-88.

Gros, B. (2016). The design of smart education environments. Smart Learning Environments, 3(15), 1-11.

Hariharasudan, A. \& Kot, S. (2018). A scoping review on digital English and Education 4.0 for Industry 4.0. Social Sciences, 7, 1-13.

Hayati, D. \& Hashemy, A. (2013). Communication technologies and virtual learning environment (VLE) in teaching literature. International Journal of Innovation, Management and Technology, 4(2), 181-184.

Hussin, A. (2018). Education 4.0 made simple: Ideas for teaching. International Journal of Education \& Literacy Studies, 6(3), 92-98.

Ibarra, D., Ganzarain, J., \& Igartua, J. (2018). Business model innovation through Industry 4.0: A review. Procedia Manufacturing, 22, 4-10.

Islam, I. (2018). Automation and the future of employment: Implications for India. South Asian Journal of Human Resources Management, 5(2), 234-243.

Kara, N. \& Sevim, N. (2013). Adaptive learning systems: Beyond teaching machines. Contemporary Educational Technology, 4(2), 108-120.

Khaleel, F., Ashaari, N., Wook, T., \& Ismail, A. (2016). Gamification elements for learning applications. International Journal on Advanced Science, Engineering and Information Technology, 6(6), 868-874.

Kinshuk (2016). Designing adaptive and personalized learning environments (Interdisciplinary approaches to educational technology). Arbingdon, UK: Routledge.

Laamarti, F., Eid, M., \& Saddik, A. (2014). An overview of serious games. International Journal of Computer Games Technology, Article ID 358152, 1-15.

Liao, Y., Deschamps, F., Loures, E., \& Ramos, L. (2017). Past, present and future of Industry 4.0 - A systematic literature review and research agenda proposal. International Journal of Production Research, 55(12), 3609-3629.

Lonkaew. K. (2016). When Thailand 4.0 was driven by Education 2.0. Saan-Punya, 26, 92-97.

Martín-Gutíerrez, J., Mora, C., Añorbe-Díaz, B., \& González-Marrero, A. (2017). Virtual technologies trends in education. EURASIA Journal of Mathematics Science and Technology Education, 13(2), 469-486.

Martinaitis, Z. (2014). Measuring skills in Europe. European Journal of Training and Development, 38(3), 198-210.

Murray, M. \& Pérez, J. (2015). Informing and performing: A study comparing adaptive learning to traditional learning. Informing Science: the International Journal of an Emerging Transdiscipline, 18, 111-125.

Papanastasiou, G., Drigas, A., Skianis, C., \& Lytras, M. (2017). Serious games in K-12 education: Benefits and impacts on students with attention, memory and developmental disabilities. Program, 51(4), 424-440. 
Popenici, S. \& Kerr, S. (2017). Exploring the impact of artificial intelligence on teaching and learning in higher education. Research and Practice in Technology Enhanced Learning, 12(22), 1-13.

Puncreobutr, V. (2016). Education 4.0: New challenge of learning. St. Theresa Journal of Humanities and Social Sciences, 2(2), 92-97.

Queirós, A., Faria, D., \& Almeida, F. (2017). Strengths and limitation of qualitative and quantitative research methods. European Journal of Education Studies, 3(9), 369-387.

Richert, A., Plumanns, L., Gross, K., Schuster, K., \& Jeschke, S. (2015). Learning 4.0: Virtual immersive engineering education. Digital Universities: International Best Practices and Applications, 2, 51-66.

Rojko, A. (2017). Industry 4.0 concept: Background and overview. International Journal of Interactive Mobile Technologies, 11(5), 77-90.

Sailer, M., Hense, J., Mayr, S., \& Mandl, H. (2017). How gamification motivates: An experimental study of the effects of specific game design elements on psychological need satisfaction. Computers in Human Behavior, 69, 371-380.

Schönsleben, P., Fontana, F., \& Duchi, A. (2017). What benefits do initiatives such as Industry 4.0 offer for production locations in high-wage countries? Procedia CIRP, 63, 179-183.

Sera, L. \& Wheeler, E. (2017). Game on: The gamification of the pharmacy classroom. Currents in Pharmacy Teaching and Learning, 9, 155-159.

Shahroom, A. \& Hussin, N. (2018). Industrial revolution 4.0 and education. International Journal of Academic Research in Business and Social Sciences, 8(9), 314-319.

Shi, Y. \& Shih, J. (2015). Game factors and game-based learning design model. International Journal of Computer Games Technology, Article ID 549684, 1-11.

Simões, J., Redondo, R., \& Vilas, A. (2013). A social gamification framework for a k-6 learning platform. Computers in Human Behavior, 29(2), 345-353.

Slimani, A., Yedri, O, Elouaai, F., \& Bouhorma, M. (2016). Towards a design approach for serious games. International Journal of Knowledge and Learning, 11(1), 58-81.

Sung, Y., Cho, S., Um, K., Jeong, Y., Fong, S., \& Cho, K. (2013). Human-robot interaction learning using demonstration-based learning and $Q$-Learning in a pervasive sensing environment. International Journal of Distributed Sensor Networks, 1, 1-8.

Tsekleves, E., Cosmas, J., \& Aggoun, A. (2016). Benefits, barriers and guideline recommendations for the implementation of serious games in education for stakeholders and policymakers. British Journal of Educational Technology, 47(1), 164183.

Vlachopoulos, D., \& Makri, A. (2017). The effect of games and simulation on higher education: A systematic literature review. International Journal of Educational Technology in Higher Education, 14(22), 1-33.

Xing, B. \& Marwala, T. (2017). Implications of the fourth industrial age for higher education. Thinker: For the Thought Leaders, 73, 10-15.

Zhu, Z., Yu, M., \& Riezebos, P. (2016). A research framework of smart education. Smart Learning Environments, 3(1), 1-17. 
CONTEMPORARY EDUCATIONAL TECHNOLOGY, 2019, 10(2), 120-136

DOI: hpps://doi.org/10.30935/cet.554469 - TYPE: Research Article

Zichermann, G. \& Cunningham, C. (2011). Gamification by design. Implementing game mechanics in Web and mobile apps. Sebastopol, California: O'Reilly.

Zimmer, T. (2014). Rethinking higher education: A case for adaptive learning. Forbes Education. Retrieved on 10 December 2018 from http://www.forbes.com/sites/ccap/2014/10/22/ rethinking-higher-ed-a-case-for-adaptive-learning/

Correspondence: Fernando Almeida, Ph.D., Lecturer, Department of Informatics Engineering, Faculty of Engineering, University of Porto, Porto, Portugal 